\title{
BIOACTIVE MOLECULES FROM EUCALYPTUS ESSENTIAL OIL AS POTENTIAL INHIBITORS OF COVID 19 CORONA VIRUS INFECTION BY MOLECULAR DOCKING STUDIES
}

\author{
Arun Dev Sharma*, Inderjeet Kaur \\ PG Dept of Biotechnology, Lyallpur Khalsa College, Jalandhar, Punjab, India \\ *Corresponding author; E-mail: arundevsharma47@gmail.com
}

(Received April 28, 2020; Accepted May 11, 2020)

\begin{abstract}
Across the world, COVID-19, a positive single-stranded RNA virus member of corona virus family, is spreading its tentacles due to lack of drugs at present causing $15 \%$ mortality worldwide due to cough, fever and respiratory problems cause more than. Due to its vital role in polyprotein processing necessary for coronavirus reproduction, the main viral proteinase (Mpro/3CLpro) has recently been regarded as a suitable target for drug design against SARS infection. The present in silico docking study was designed to evaluate the effect of potent 12 bioactive molecules present in essential oils of eucalyptus plant leaves. In the present study, molecular docking studies were conducted using a 1click dock. Docked complex analysis was carried out using the Biovia Discovery studio, Chimera and VMD tools. Active sites were obtained from CAST P analysis. The calculated parameters such as RMSD, docking score indicated effective binding of bioactive essential oil molecules, especially Jensenone, to COVID-19 proteinase. Active site prediction further validated the role of active site residues in ligand binding. Molecular interactions results indicated that Mpro/eucalyptol complexes form hydrophobic interactions, hydrogen bond interactions and strong ionic interactions. Therefore, eucalyptus essential oil bioactive compounds may represent potential treatment potential to act as COVID-19 Mpro inhibitor. However, further research is necessary to investigate their potential medicinal use.
\end{abstract}

Keywords: Bioactive compounds, COVID-19, Essential oil, Molecular docking.

\section{INTRODUCTION}

COVID-19 continues to spread rapidly and affect people across the globe, it is important to look at how bioactive compounds and functional foods may prove beneficial in the fight against viral diseases. So, there is a need to submit research pertaining to the role of bioactive compounds and functional foods in the management of COVID-19 and related viruses. This global pandemic has provided us with a unique and urgent opportunity to advance research and explore how bioactive compounds and functional foods can be used to boost the immune system and fight off viral diseases. Symptoms are flu-like and can include fever, muscle and body aches, coughing, and sore throat. Symptoms may appear 5-6 days after infection. As of April 14,2020 , over 2,000000 cases of COVID-19 have been confirmed worldwide, over 18,000 of 
which have resulted in death. At present, no specific therapies for COVID-19 are available and research regarding the treatment of COVID-19 is infancy. However, the measures that have been implemented remain limited to preventive and supportive therapies, designed to prevent further complications and organ damage (LU, 2020). Some preliminary studies have investigated potential combinations that include anti-malarial drug hydroxychloroquine and nelfinavir. Anti-HIV vaccines can be used to treat COVID-19 infections also. From COVID 19, protein namely Mpro/chymotrypsin-like protease (3CLpro), was cited as a key target to combat COVID 19 replication (LIU and WANG, 2020). Mpro/3CLpro enzyme has been implicated in spike, membrane, envelop, nucleoprotein, replicase, and polymerase activity of viruses. Therefore, based on its vital role in various replication related biological processes in COVID 19, Mpro/3CLpro enzyme has been considered as a suitable target for viral inhibitor development as an approach toward SARS.

Essential oils, among the category of secondary metabolites, from aromatic plants, are highly volatile complex mixtures of various chemical molecules belonging to terpenes, oxygenated derivatives, aliphatic hydrocarbons, esters, alcohols and other aromatic compounds (GOODGER et al., 2016, YANG et al., 2018). The terms "essential oil", "volatile oil", or "etheric oil" are used to designate liquid substances emerged from specialized glands from plant cells. The essential oil contains a number of complex bio-structures formed by different molecules, each having specific bioactivity (antimicrobial, antiviral, fungicidal, insecticidal and herbicidal). The broad spectrum and versatility of essential oils have been ascribed to different bio-structures and unique chemical composition that act synergistically. Their chemical composition is greatly influenced by environmental factors that can affect the secretion of secondary metabolites from aromatic plants. Essential oils by virtue of having antimicrobial and antioxidant activities have great potential in the cosmetic and pharmaceutical industries. Therefore, during time, great attention has been paid to essential oils that may be developed as medicines (RODRÍGUEZ et al., 2020). Essential oils have been used empirically as antimicrobial or antiviral agents to combat microbial infections, however, a little is known about its mechanism of action.

In the present study, we investigated essential oil molecules from the eucalyptus plant as potential inhibitor candidates for COVID-19 Mpro. Eucalyptus (family: Myrtaceae) is one of the most widely spread genera, commonly referred to as the Tasmanian gum plant. It is fast growing, evergreen, native to Tasmanian and South-East Australia. It is used to extract Oleum Eucalypti (eucalyptus oil) that is extracted in many countries like China, India, South Africa, Brazil and Tasmania, as a raw material in the pulp, cosmetic, pharmaceutical, food beverage, aromatherapy and phototherapy. This study will pave a way to other researchers with opportunities to find out the right drug to combat COVID-19.

\section{MATERIAL AND METHODS}

\section{Proteins/Macromolecules}

COVID-19 3CLpro/Mpro structures were obtained from the Protein Data Bank (https://www.rcsb.org/). The native ligands for 3CLpro/Mpro structures are shown in Fig 1. The 3-dimensional (3D) structure of Eucalyptus essential oil molecules (Fig. 1) were obtained from PubChem (https://pubchem.ncbi.nlm.nih.gov/).

\section{Determination of Active Sites}

The amino acids in the active site of a protein were determined using the Computed Atlas for Surface Topography of Proteins (CASTp)

(http://sts.bioe.uic.edu/castp/index.html?2011). 


\section{Molecular Docking}

Docking studies of essential oil bioactive molecules over COVID-19 Mpro were studied using 1-click docking (https://mcule.com/apps/1-click-docking/) software.

\section{Binding Mode of Docked Complexes}

The docked complex structure output formats were submitted into Biovia Discovery Studio Visualizer 2020 and Chimera tools in order to study 3D conformations, surface analysis and to map the interaction of the resulting docked complex (https://projects.biotec.tudresden.de/plip-web/plip/index).

\section{Admet SAR}

AdmetSAR is a comprehensive web-based tool for predicting ADMET properties of candidate molecules (http://lmmd.ecust.edu.cn/admetsar2/). It predicts the pharmacokinetic properties such as Absorption, Distribution, Metabolism, Excretion and Toxicity.

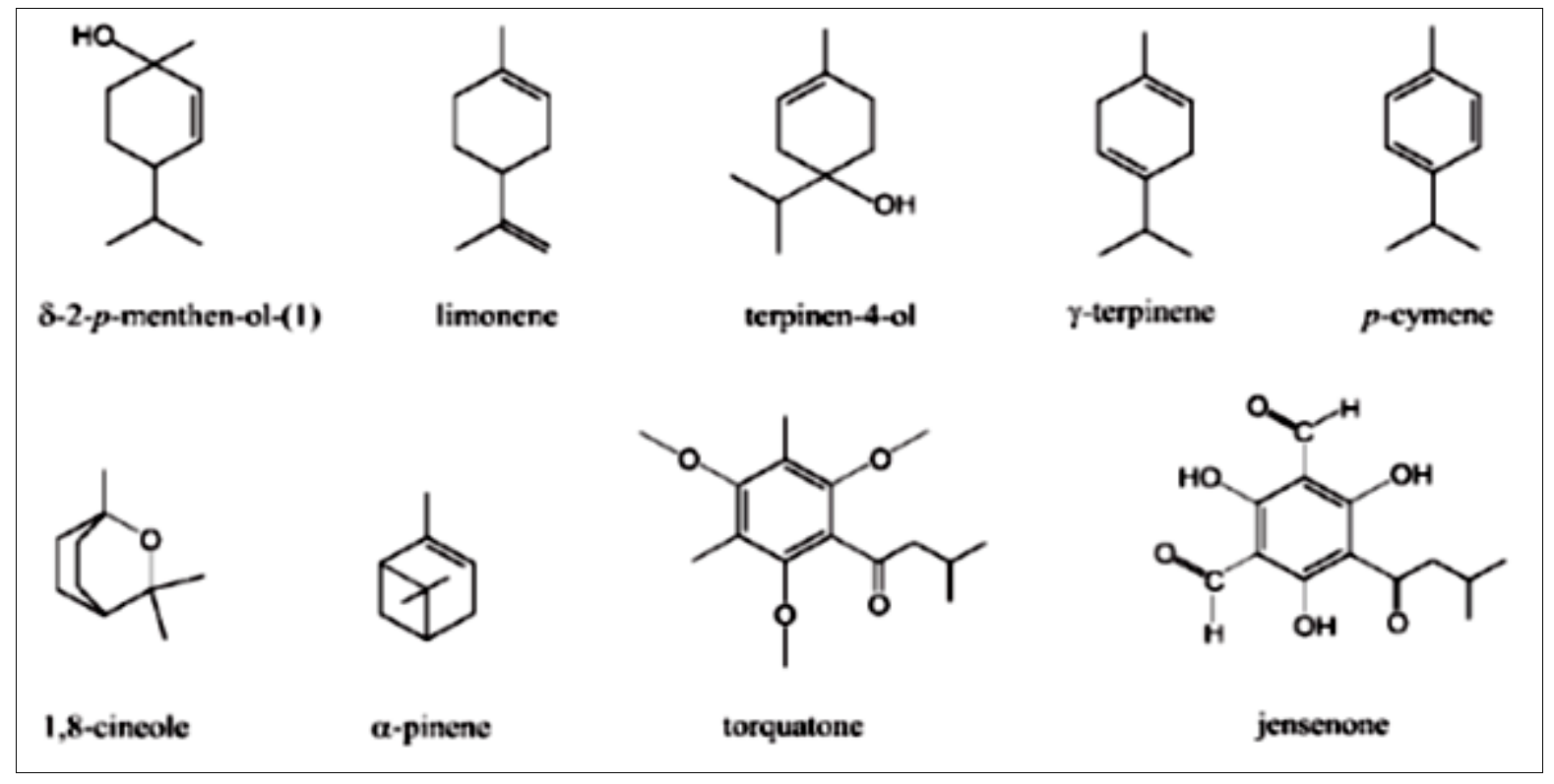

Fig 1: Molecules from Eucalyptus essential oil used in this study.

\section{RESULTS AND DISCUSSION}

Corona viruses $(\mathrm{CoVs})$ are a group of viruses that infect animals and humans. $\mathrm{CoV}$ infections affect animals in various ways, like respiratory, fever, cold, digestive, and liver systems of humans and animals (RODRÍGUEZ et al., 2020). It is the main protease (Mpro) found in the $\mathrm{CoV}$ associated with the severe acute respiratory syndrome (SARS), which can be accessed in PDB, and was suggested to be a potential drug target for 2019-nCov (LU, 2020). In $\mathrm{CoV}$, the Mpro protein is involved in virus proteolytic maturation and has been examined as a potential target protein by inhibiting the cleavage of the viral polyprotein to prevent the spread of infections replication. Since SARS-CoV Mpro and the 2019-nCoV Mpro are 96\% identical, so these proteases may be used as potential therapeutic targets (LIU and WANG, 2020). In this study, we focused on structural biology aspects of Mpro/3CL pro protein which is based on the availability and retrieval of a receptor structure from PDB database. 
The ligands, as shown in Fig. 1, were docked to main protease (Mpro) or 3C-like protease (3CLpro) using the 1-click software. The various docking 3D representations and interactions are shown in Fig 2. Using 1-click docking tool, Mpro/3CLpro protein revealed four different poses.

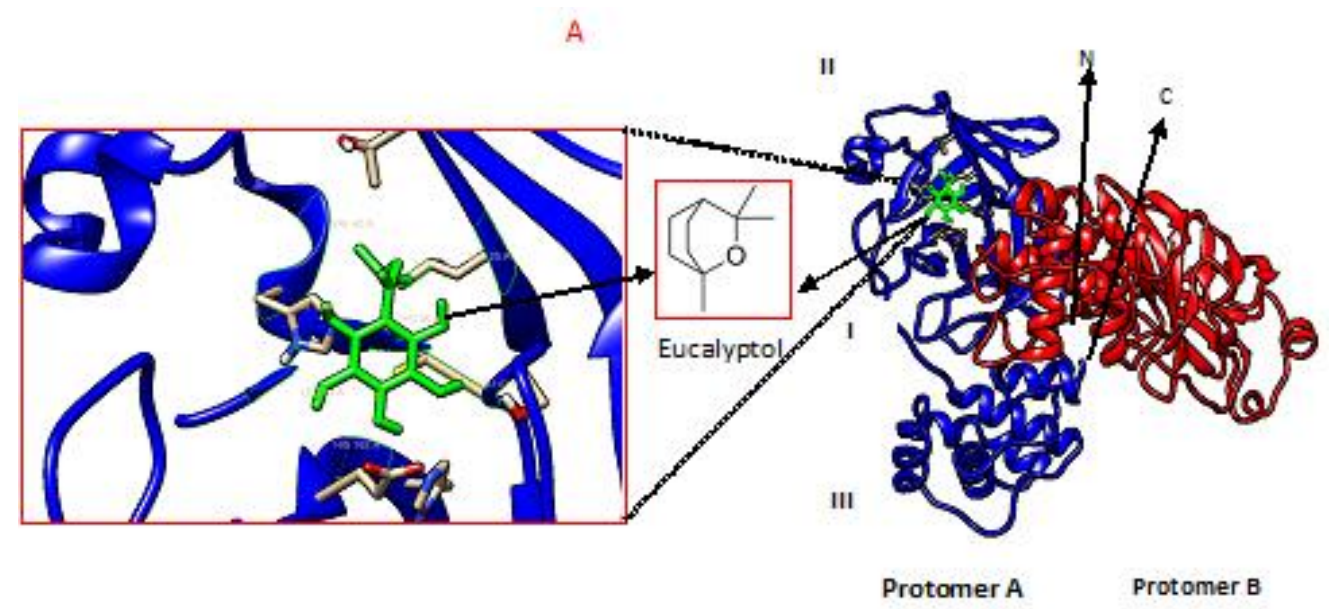

B

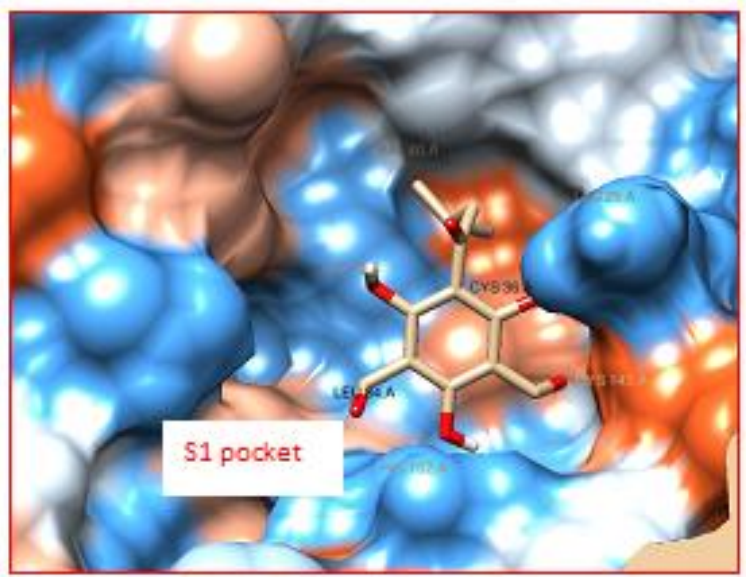

Figure 2: Three-dimensional docked structure (A) and surface view (B) of SARS-CoV-2 Mpro with Jensenone. One protomer of the dimer is shown in light blue, the other one in red. Domains are labeled by Roman numbers.

Chain termini are labeled $\mathrm{N}$ and $\mathrm{C}$ for ligand interacting Protomer A (blue).

Based on the dock score and the pose with the highest negative values indicated maximum binding affinity is shown in Table 1. Among all molecules, Jensenone exhibited the highest affinity with Mpro/3CLpro protein with maximum docking score followed by Cis-p-2Menthen-1-ol. The high affinity of drug compounds depends on the amount and the type of bonding that occurs with the active site of the protein. As indicated in Fig. 1 Jensenone forms many chemical bonds with a pocket are present in domains I and II of Mpro, including hydrogen bonds and hydrophobic bonds. Domains I and II, representing residues 10-99 and 100-182, respectively, are six-stranded antiparallel $\beta$-barrels that harbor the substrate-binding site between them. A globular cluster of five helices, Domain III (residues 198-303), is involved in regulating dimerization of the Mpro, mainly by a salt-bridge interaction between both protomers. The tight dimer formed by SARS-CoV-2 Mpro has a contact interface, predominantly between domain II of protomer A and the NH2-terminal residues (N-finger") of protomer $\mathrm{B}$, with the two molecules oriented perpendicular to one another (Fig. 2). It was cited that for Mpro enzyme catalytic activity, dimerization is essential because the $\mathrm{N}$-finger of each of the 
two protomers interacts and thereby helps shape the $S 1$ pocket of the substrate-binding site. To reach this interaction site, the $\mathrm{N}$-finger is squeezed in between domains II and III of the parent monomer and domain II of the other monomer.

Therefore, the affinity of these molecules was higher compared with other compounds (LIU and WANG, 2020). Further, as indicated in Table 1, almost all the essential oil molecules formed hydrogen bonds and hydrophobic interactions with active site amino acids of Mpro/3CLpro proteins of COVID-19 (Figs 3 and 4). CAST-P server also revealed the presence of four major cavities having active sites residues in Mpro/3CLpro proteins of COVID-19 (Fig. 5). Several compounds, such as flavonoids, terpenoids and phenolics from essential oils, have been reported to show antiviral bioactivities (GOODGER et al., 2016; ZAKARYAN et al., 2017). We investigated that Eucalyptus essential oil components like Jensenone or Eucalyptol $(1,8$ cineole) as a potential inhibitor of the COVID-19 Mpro. Hydroxy groups (-OH), ketone groups $(=\mathrm{O})$ and ether groups (-O-) in Jensenone and other compounds are predicted to play roles amino acid residue interactions at the active site of COVID-19 Mpro. Plip identified interactions such as hydrophobic residues interactions, hydrogen bond interaction and van der Waals interactions within the peptide-protein complexes. According to the Plip server and Biovia studio results as shown in Table 1 and Fig. 3, Mpro protein formed complexes with ligands molecules from eucalyptus essential oil by forming various interactions. For instance, eucalyptol formed hydrophobic interactions with GLU14. Result of the present study shown that LEU25 was a critical residue for binding of Jensenone to Mpro protein. PHE138 participated in hydrophobic interaction with Citronellal. Similarly, hydrogen bond interactions were also detected. GLY141, SER142 and GLU164 amino acids were responsible for Cis-p-2Menthen-1-ol binding with COVID-19 protein. It was postulated that these protein-protein interactions might inhibit the formation of the beta-barrel motif of Mpro/3CLpro. As shown in Table 1 and Fig. 3, ALA44 reside was involved in binding with Geranyl acetate. Notably, only in Phenethyl phenylacetate, Pi-sulfur bond interaction was observed (Fig. 3). C-H interactions were also detected in Eucalyptus and Citronellal Mpro complexes. It was observed that the majority the H-bonds and hydrophobic interactions were observed with amino acids in the COVID-19 Mpro active sites. Further studies may help to understand the role of these residues in drug binding mechanism.

In silico pharmacokinetic analysis of eucalyptus was conducted using ADMET. The pharmacokinetics of a drug depends on its absorption, distribution, metabolism, excretion and toxicity. Previously several ligands and drug candidate compounds have been selected, as per criteria of Lipinski's rule of five (LIPINSKI, 2004). So, the ligands that did not incur more than two violations of Lipinski's rule (rule of five; RO5) could be used in molecular docking experiments with the target protein.

The drug scanning results (Table 2) showed that herbal ligands used in this study was accepted by Lipinski's rule of five. Topological polar surface area (TPSA) data indicated that ligands are good at permeating cell membranes. For drug molecules to penetrate the bloodbrain barrier (BBB) (and thus act on receptors central nervous system), a PSA less than 90 angstroms squared is usually needed. 
Table 1: Docking analysis of Eucalyptus essential oils molecules.

\begin{tabular}{|c|c|c|c|c|c|}
\hline Model name & $\begin{array}{l}\text { Docking } \\
\text { score (-) }\end{array}$ & RMSD & $\begin{array}{c}\text { Hydrogen } \\
\text { bonds }\end{array}$ & $\begin{array}{c}\text { Hydrophobic } \\
\text { interactions }\end{array}$ & $\begin{array}{c}\text { Total no } \\
\text { active sites } \\
\text { residues } \\
\text { involved in } \\
\text { interactions }\end{array}$ \\
\hline & & & $\begin{array}{c}\text { Amino } \\
\text { acid } \\
\text { residues }\end{array}$ & $\begin{array}{l}\text { Amino acid } \\
\text { residues }\end{array}$ & \\
\hline Eucalyptol & 4.0 & 0 & - & $\begin{array}{c}\text { CYS143 } \\
\text { HIS161 } \\
\text { GLU164 }\end{array}$ & 3 \\
\hline Citronellol & 4.2 & 0 & $\begin{array}{c}\text { SER1 } \\
\text { CYS143 } \\
\text { HIS161 } \\
\text { GLU164 }\end{array}$ & MET163 & 4 \\
\hline Citronellal & 4.2 & 0 & $\begin{array}{l}\text { GLY142 } \\
\text { SER143 } \\
\text { CYS144 }\end{array}$ & $\begin{array}{c}\text { PHE138 } \\
\text { MET13 } \\
\text { GLU164 }\end{array}$ & 4 \\
\hline Phenethyl phenylacetate & 4.7 & 0 & $\begin{array}{l}\text { GLY142 } \\
\text { SER143 } \\
\text { CYS144 }\end{array}$ & GLU14 & 3 \\
\hline Geranyl acetate & 3.7 & 0 & $\begin{array}{l}\text { THR23 } \\
\text { ALA44 }\end{array}$ & $\begin{array}{c}\text { LEU25 } \\
\text { HIS39 }\end{array}$ & 3 \\
\hline Limonene & 3.7 & 0 & - & $\begin{array}{c}\text { HIS39 } \\
\text { MET163 } \\
\text { GLU164 }\end{array}$ & 3 \\
\hline 4-terpineol & 5.0 & 0 & $\begin{array}{l}\text { HIS161 } \\
\text { CYS143 }\end{array}$ & $\begin{array}{c}\text { HIS39 } \\
\text { MET47 } \\
\text { GLU164 }\end{array}$ & 5 \\
\hline P-cymene & 3.8 & 0 & - & $\begin{array}{l}\text { MET163 } \\
\text { GLU164 }\end{array}$ & 2 \\
\hline Alpha-pinene & 4.0 & 0 & - & $\begin{array}{l}\text { ASN140 } \\
\text { CYS143 } \\
\text { GLU164 }\end{array}$ & 3 \\
\hline Toruatone & 4.3 & 0 & GLU164 & $\begin{array}{c}\text { MET47,163 } \\
\text { THR23 } \\
\text { GLU164 }\end{array}$ & 4 \\
\hline Jensenone & 5.4 & 0 & $\begin{array}{c}\text { SER142 } \\
\text { CYS143 } \\
\text { HIS161 } \\
\text { GLU164 }\end{array}$ & $\begin{array}{r}\text { THR23 } \\
\text { LEU25 } \\
\text { HIS39 }\end{array}$ & 6 \\
\hline Cis-p-2-Menthen-1-ol & 5.1 & 0 & $\begin{array}{c}\text { LEU139 } \\
\text { GLY141 } \\
\text { SER142 } \\
\text { HIS12 } \\
\text { GLU164 }\end{array}$ & $\begin{array}{c}\text { LEU25 } \\
\text { CYS143 }\end{array}$ & 6 \\
\hline
\end{tabular}

Highlighted residues indicate part of active sites of Mpro protein. 

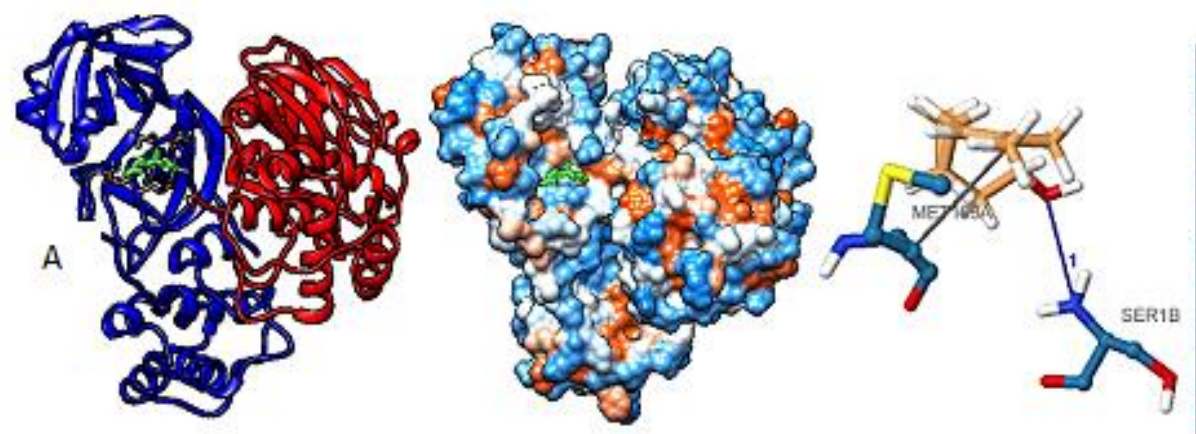

- Protein

- Water

Charge Center

Aromatic Ring Center

- Metal ion

.... Hydraphobic Interaction

- Hydragen Band

- Water Bridge

.... $\pi$-Stacking (parallel)

.... $\pi$-Stacking (perpendicular)

.... $\pi$-Cation Interactian

- Halogen Band

.... Salt Bridge
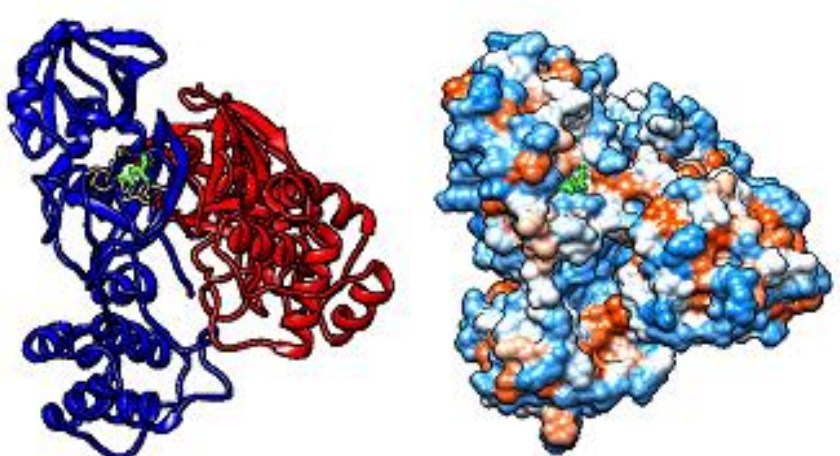

... Metal Complexation

\section{B}
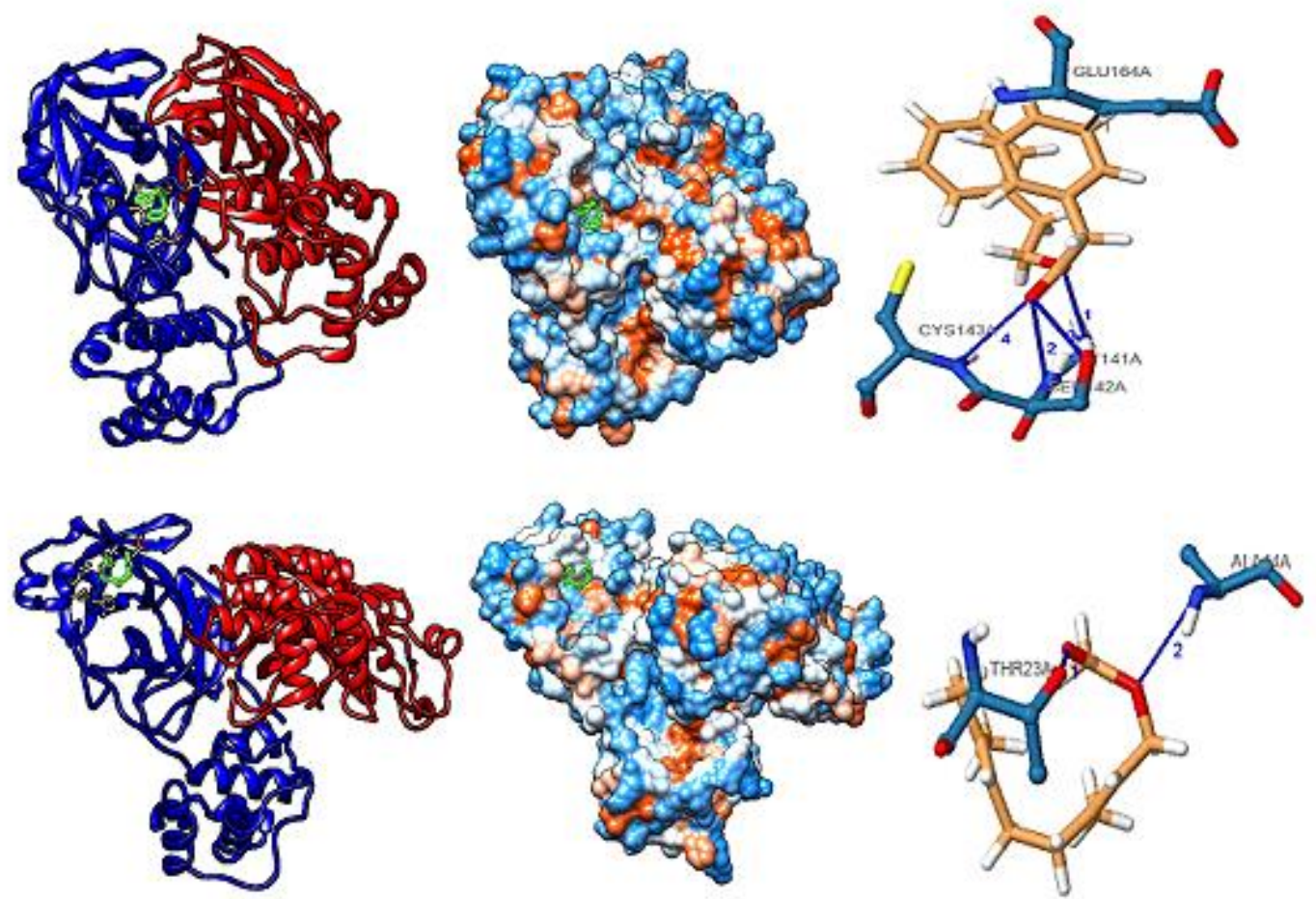

Figure 3: Docking analysis visualization of Mpro protein with different Eucalyptus oil molecules. A - Citronellol, B - Citronellal, C - Phenethyl phenylacetate, D - Geranyl acetate, 

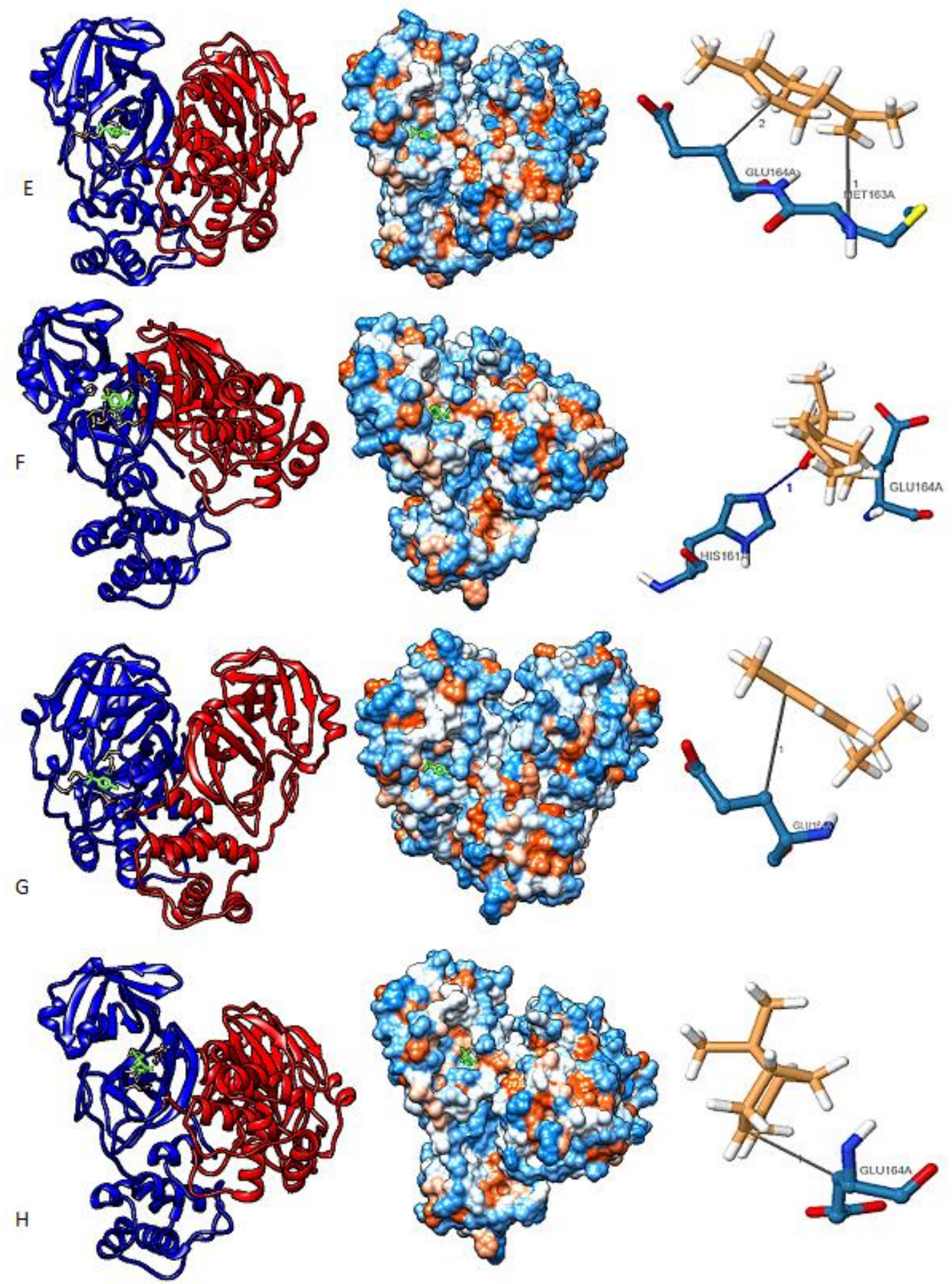

Figure 3 continued: E - Limonene, F - 4-terpineol, G - P-cymene, H - Alpha-pinene, 

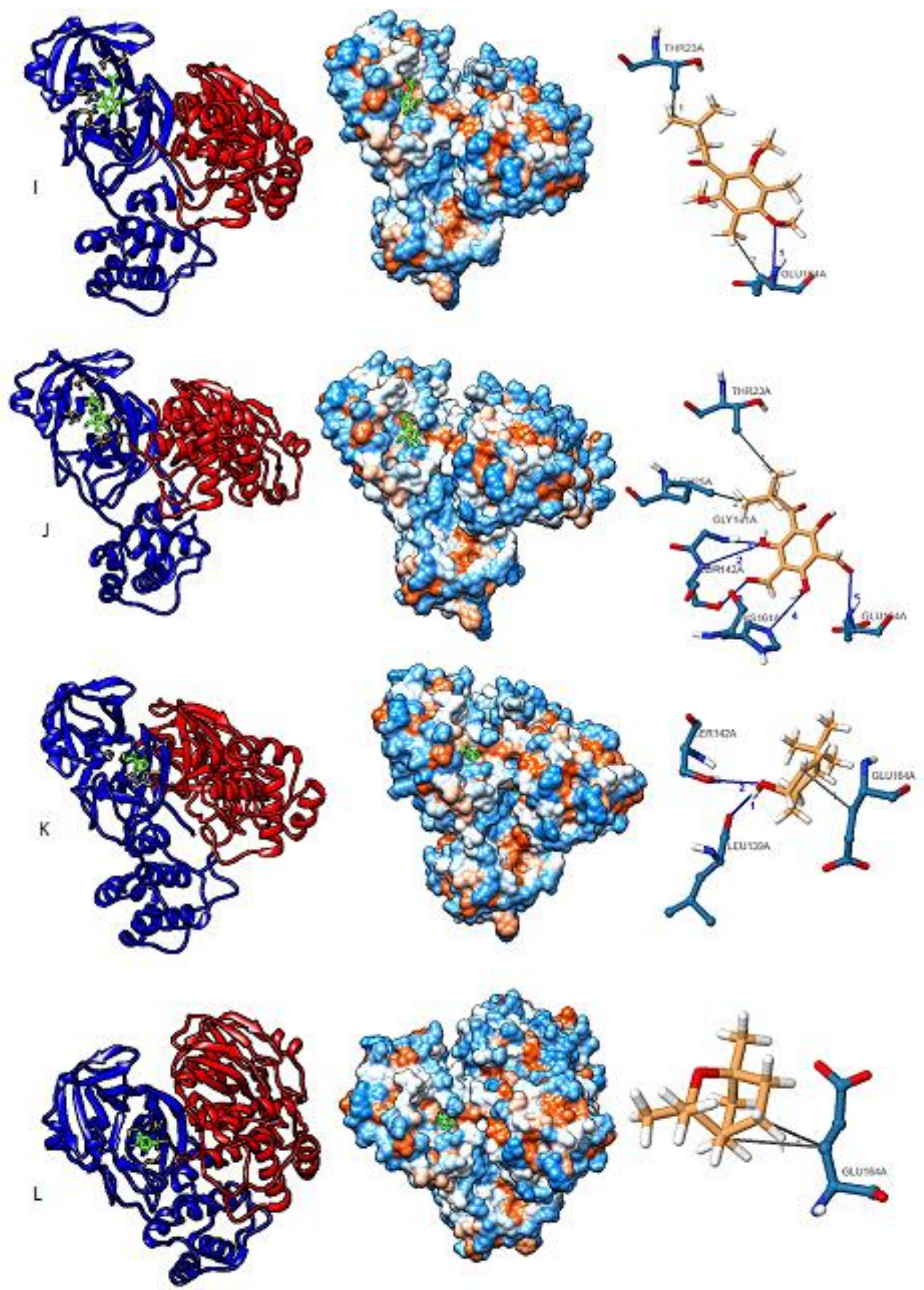

Figure 3 continued: I - Toruatone, J - Jensenone, K - Cis-p-2-Menthen-1-ol, L - Eucalyptol. 

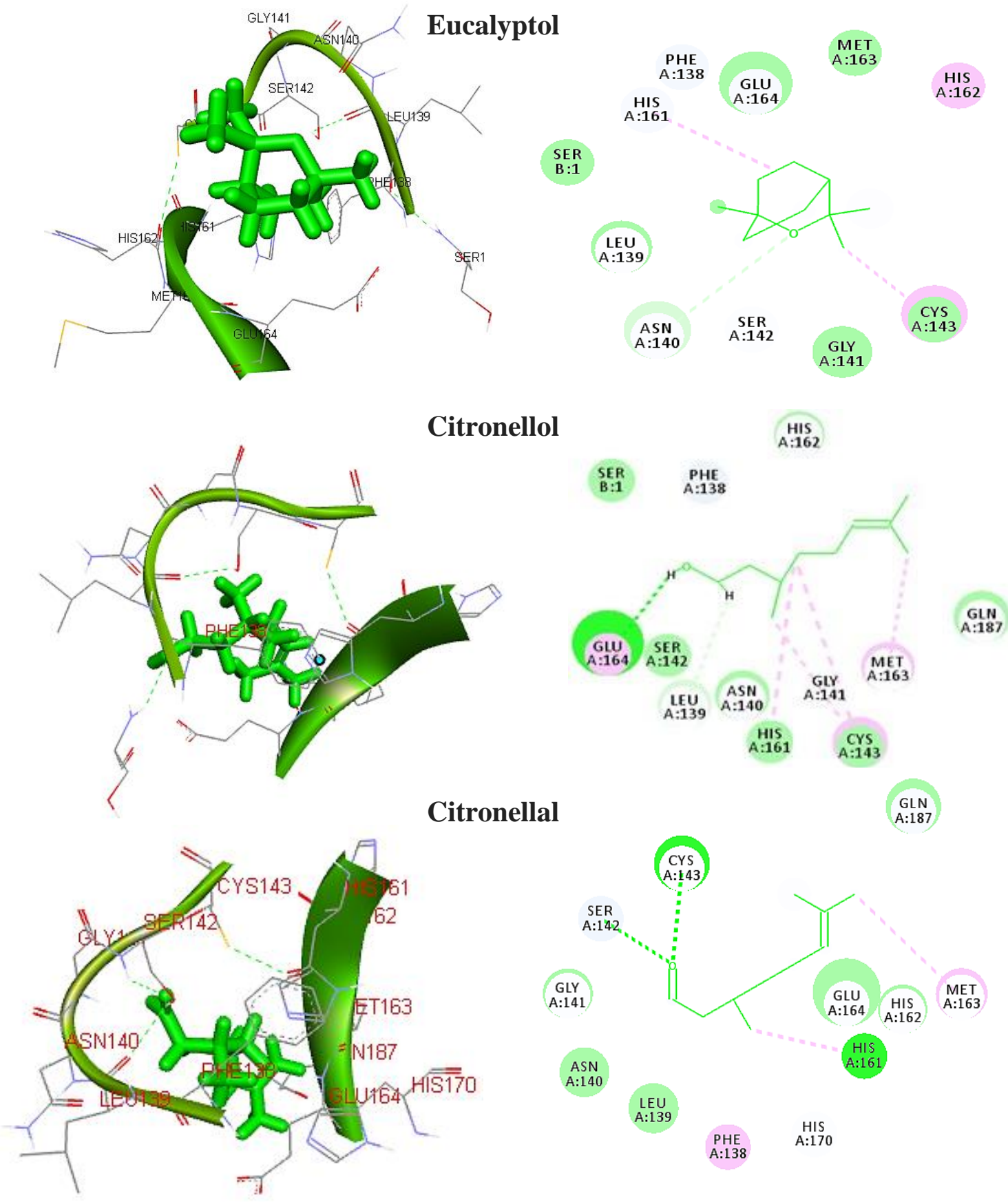

Phenethyl phenylacetate
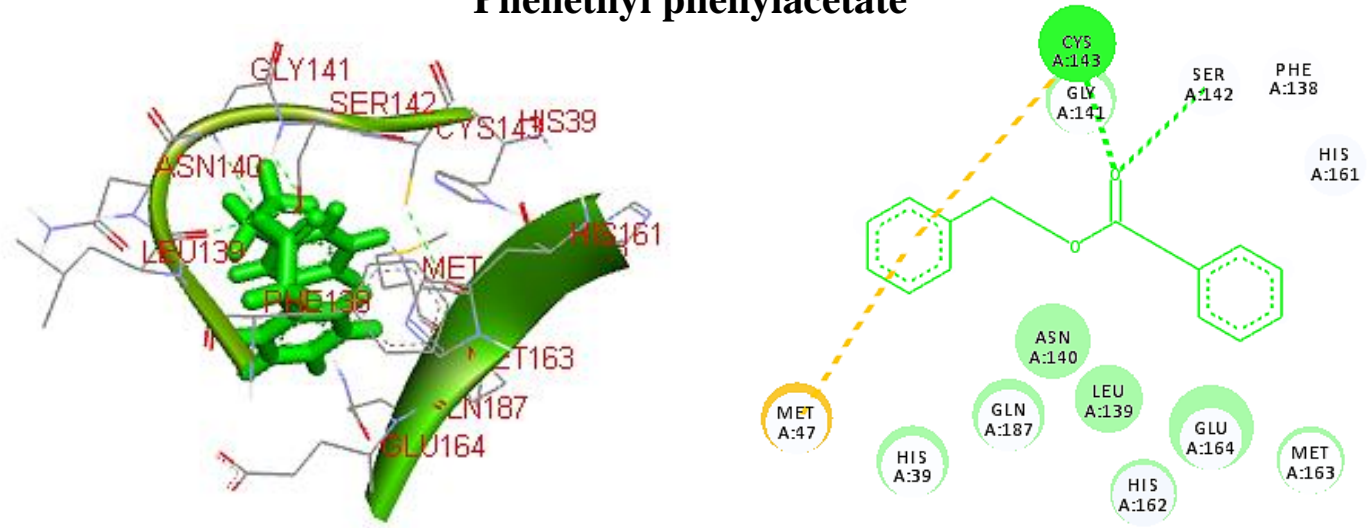

Fig 4: Molecular interactions essential oil molecules with Mpro protein. 

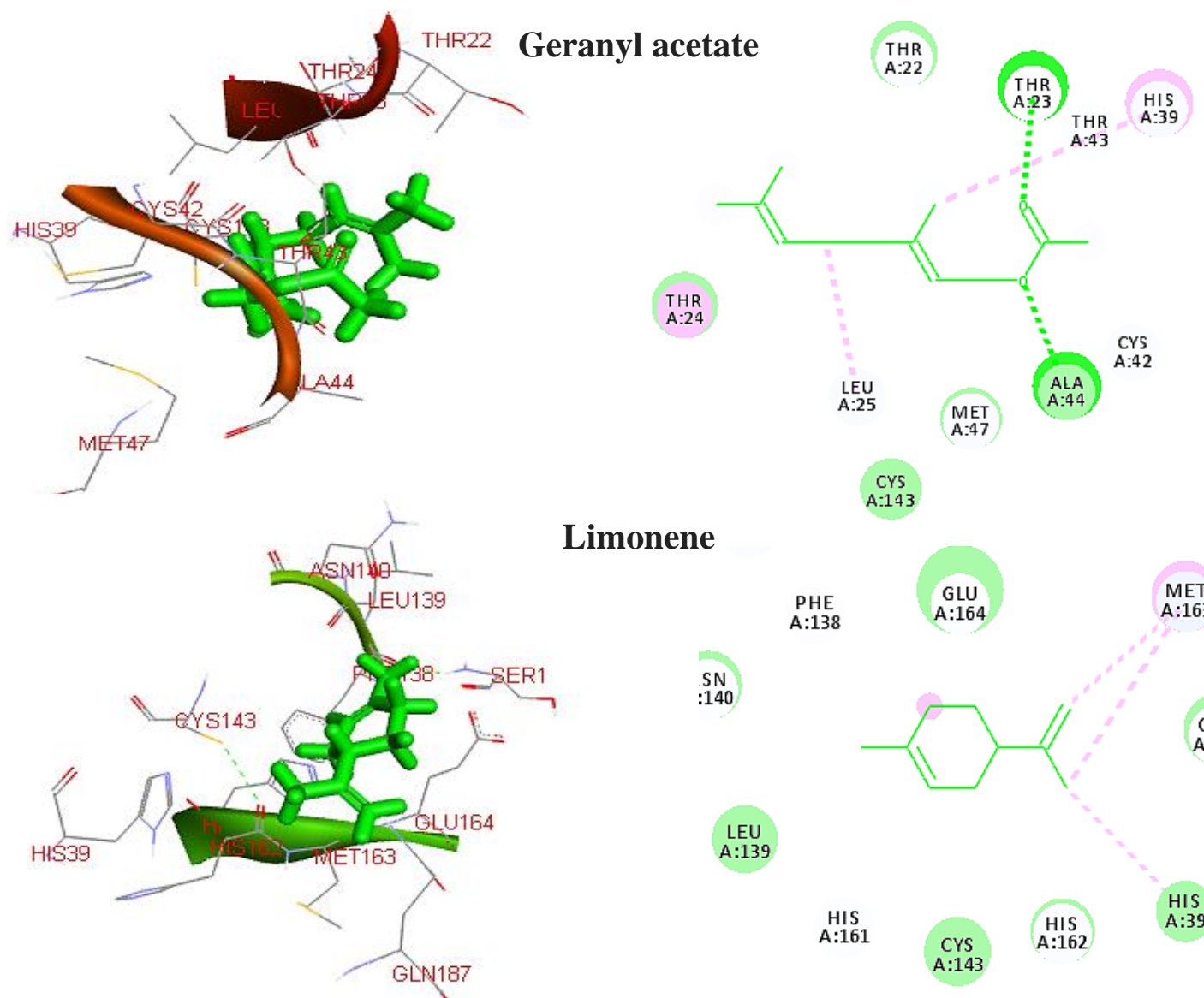

Limonene
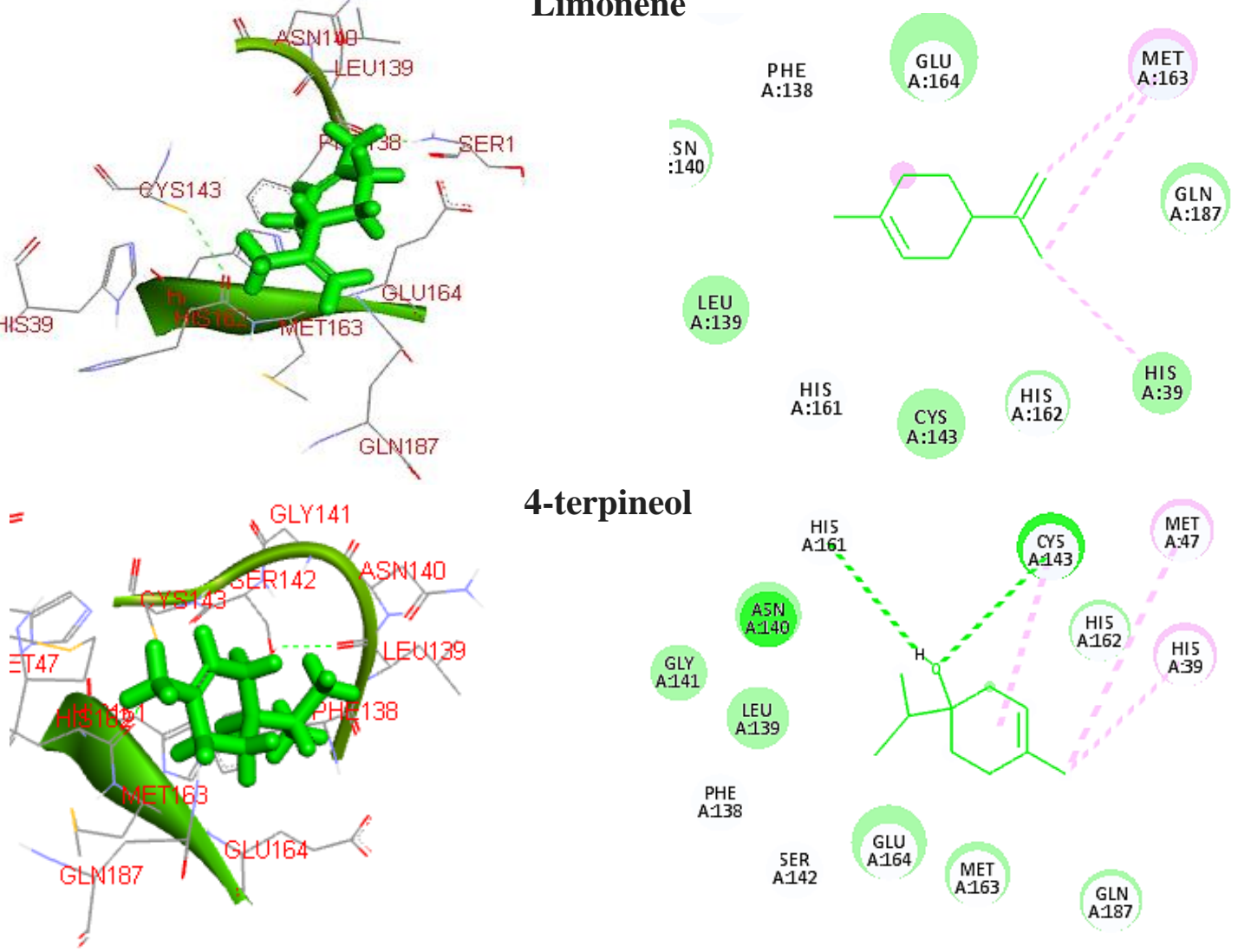

4-terpineol

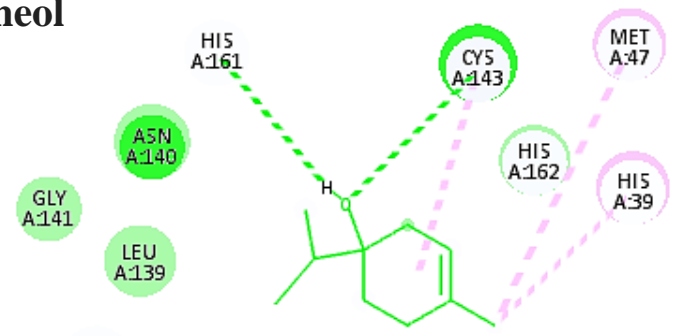

PHE

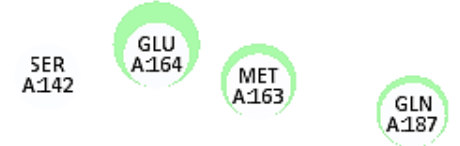

\section{P-cymene}
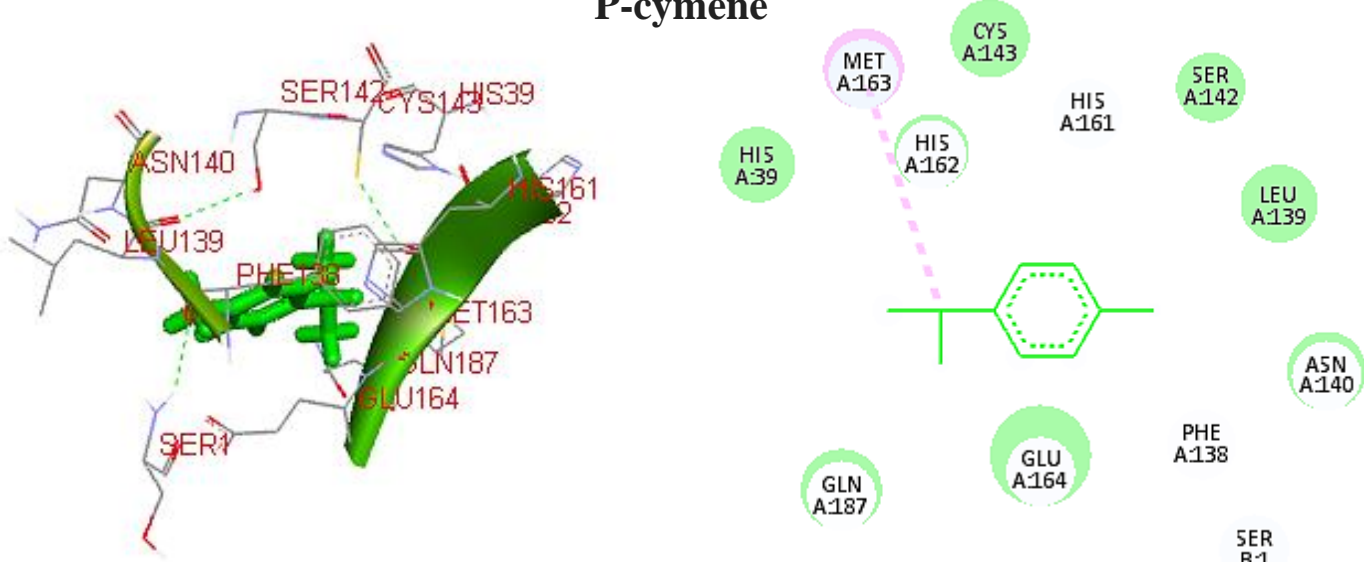

Fig 4: continued. 

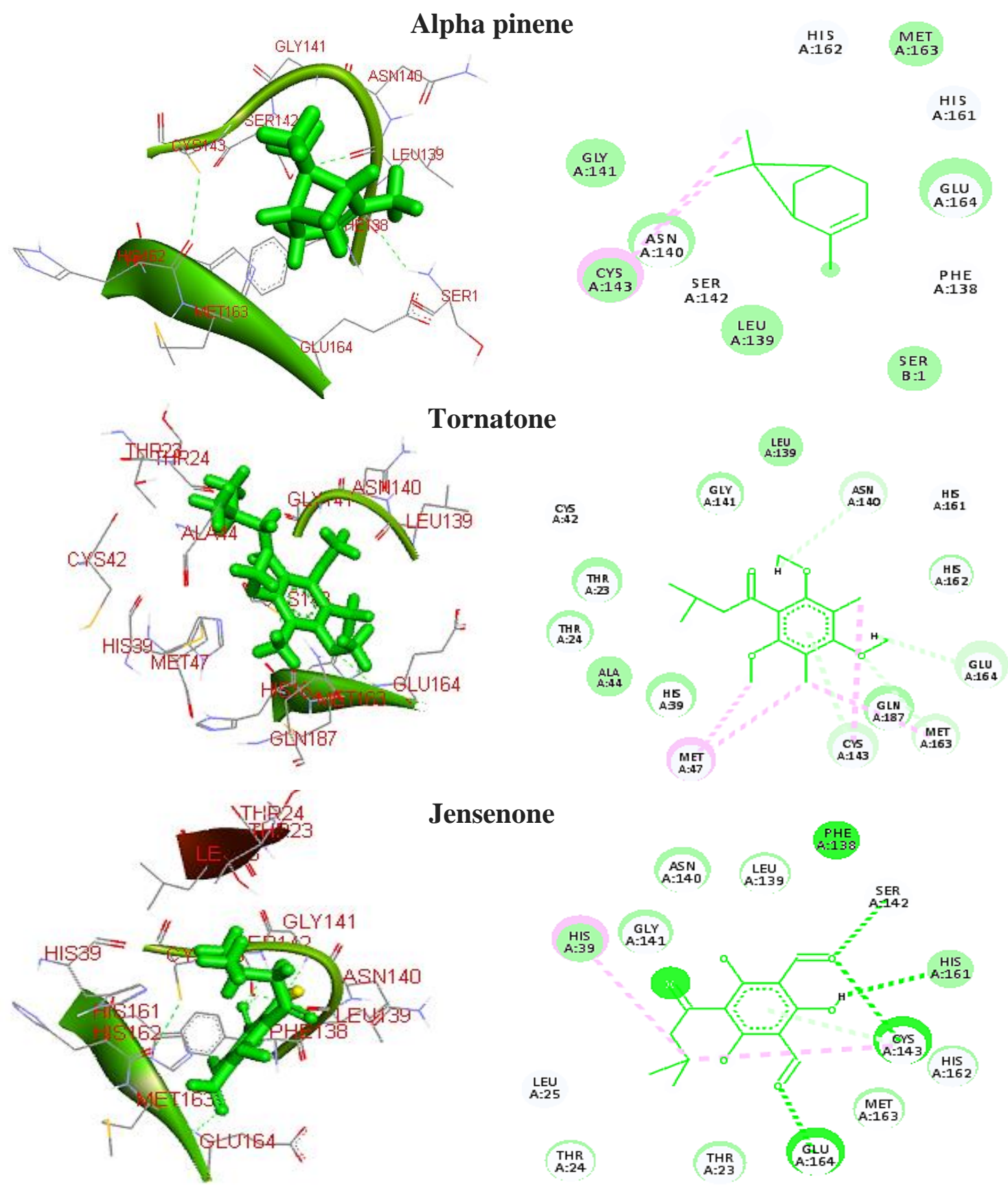

Jensenone

Cis-p-2-Menthen-1-ol
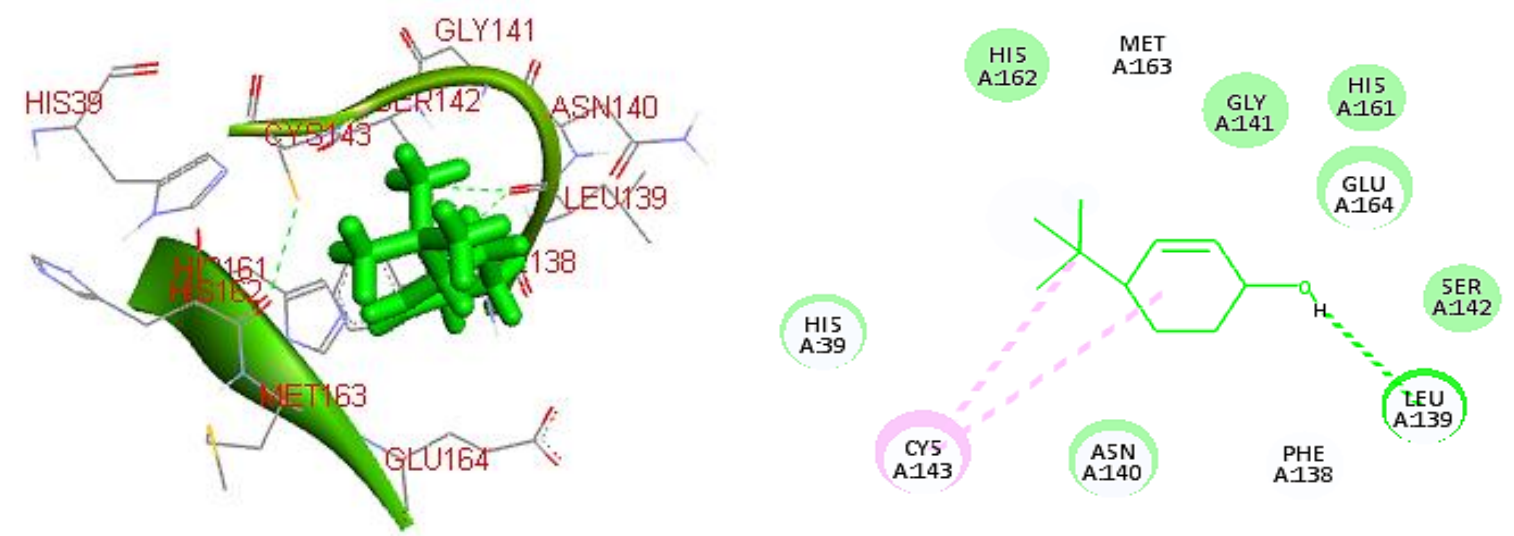

Fig 4: continued. 


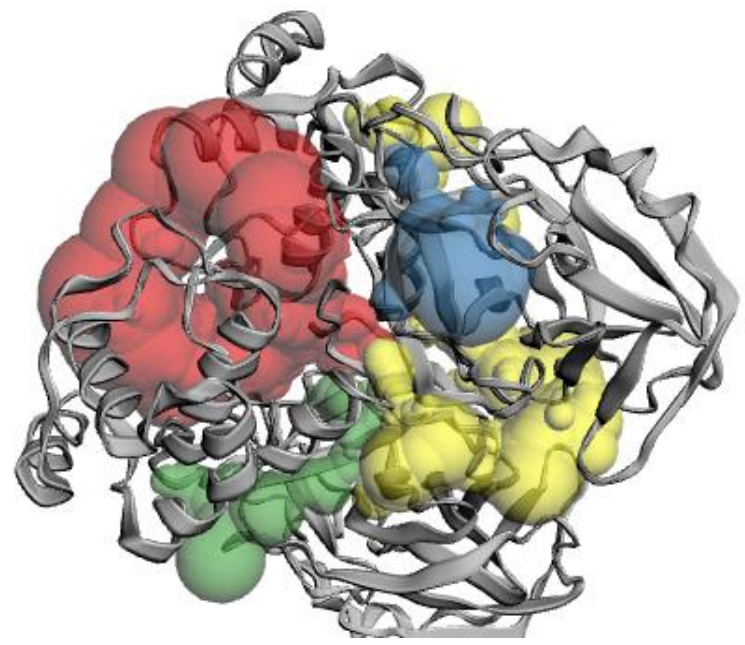

\begin{tabular}{ccc|l|l|}
\hline \multirow{2}{*}{ Pocket ID } & Area (SA) & Volume (SA) & \multicolumn{2}{c}{ Negative Volume } \\
Color & \multicolumn{1}{c}{ Active residues } \\
\hline 1 & 1689.804 & 2332.004 & Red & \\
2 & 1470.951 & 1288.702 & Yellow & \\
3 & 266.905 & 290.309 & Blue & \\
4 & 283.081 & 148.253 & Green & \\
\hline
\end{tabular}

Fig 5: Active sites of Mpro protein.

Due to poor pharmacokinetics parameters, most of the drugs in development failed during clinical trials. For human therapeutic use, these properties such as absorption, distribution, metabolism, excretion and toxicity (ADMET) are important in order to determine the success of the compound. Some important chemical descriptors correlate well with ADMET properties such as low molecular weight (MW) for oral absorption.

The distribution of the compound in the human body depends on factors such as the blood-brain barrier ( $\log$ BB) permeability which was good with ligands. The ligands showed positive results for the $\mathrm{BBB}$ profile. Most of the compounds were non-substrate to $\mathrm{P}$ glycoprotein (p-gp), which is an efflux transporter located at BBB. Consensus Log $\mathrm{P}_{\mathrm{o} / \mathrm{w}}$ (indicative of lipophilicity), also known as octanol-water partition coefficient was in a good range. It suggested that eucalyptol has optimal blood-brain-barrier penetration. It has been reported that the excretion process that eliminates the compound from the human body depends on the molecular weight. Similarly, rapid renal clearance is associated with small and hydrophilic compounds. The metabolism of most drugs that takes place in the liver is associated with large and hydrophobic compounds. Higher lipophilicity of compounds leads to increased metabolism and poor absorption, along with an increased probability of binding to undesired hydrophobic macromolecules, thereby the increasing the potential for toxicity. Gastrointestinal tract absorption (GI) of eucalyptol was high (Table 2), as substances must get absorbed from intestinal tract in order to exert a toxic effect throughout the whole body. Further, eucalyptol was non-inhibitor to cytochrome P series (CYP1-3) of enzymes, which mainly found in the liver and in the intestine involved in toxins detoxification from the body. 
Table 2: ADMET properties of ligands.

\begin{tabular}{|c|c|c|c|c|c|c|c|c|c|c|c|c|c|}
\hline & \multicolumn{5}{|c|}{ Lipinah's rule of five } & \multirow[b]{2}{*}{$\begin{array}{l}\text { GI } \\
\text { absorpti } \\
\text { on }\end{array}$} & \multirow[b]{2}{*}{$\begin{array}{l}\text { Consensus } \\
\text { Log } \mathrm{Pow} \text {. }\end{array}$} & \multicolumn{3}{|c|}{ ADMIIT properdies } & \multirow[b]{2}{*}{$\begin{array}{l}\text { CYP3.A4 } \\
\text { inhibitor }\end{array}$} & \multirow[b]{2}{*}{$\begin{array}{l}\log K_{p} \\
\text { (alin } \\
\text { permeation) }\end{array}$} & \multirow[b]{2}{*}{$\begin{array}{l}\text { Log } S \\
\text { (ESOL) }\end{array}$} \\
\hline & $\begin{array}{l}\text { Molecular } \\
\text { weight }\end{array}$ & $\begin{array}{l}\text { Num H- } \\
\text { boes } \\
\text { acceptors }\end{array}$ & $\begin{array}{l}\text { Num } \\
\text { H. } \\
\text { bond } \\
\text { dopors }\end{array}$ & $\begin{array}{l}\text { Molar } \\
\text { refractivity }\end{array}$ & $\begin{array}{l}\text { lipophilicity } \\
\log P\end{array}$ & & & TPSA & $\begin{array}{l}\text { BBB } \\
\text { perment }\end{array}$ & $\begin{array}{l}\text { P-gp } \\
\text { substrate }\end{array}$ & & & \\
\hline 1 & $154.25 \mathrm{gm}=0 \mathrm{l}$ & 1 & 0 & 47.12 & 2.58 & High & 2.67 & $\frac{9.23}{A^{2}}$ & Yo: & No & No & $-5.30 \mathrm{~cm} / \mathrm{s}$ & -2.52 \\
\hline 2 & $156.27 \mathrm{gmol}$ & 1 & 1 & 50.87 & 2.72 & High & 292 & 20.23 & Yos & No & No & $-4.48 \mathrm{~cm} / \mathrm{s}$ & -2.94 \\
\hline 3 & $154.25 \mathrm{gmol}$ & 1 & 0 & 4991 & 2.49 & High & 294 & 17.07 & Yo: & No & No & $-4.52 \mathrm{~cm} / \mathrm{s}$ & -2.88 \\
\hline 4 & $240.30 \mathrm{gmol}$ & 2 & 0 & 71.60 & 2.95 & High & 3.50 & $\begin{array}{l}26.30 \\
A^{2}\end{array}$ & Yo: & No & No & $-5.02 \mathrm{~cm} / \mathrm{s}$ & -3.87 \\
\hline 5 & $196.29 \mathrm{~g} \mathrm{~mol}$ & 2 & 0 & 60.13 & 2.83 & High & 3.21 & $\begin{array}{l}26.30 \\
A^{2}\end{array}$ & Yo: & No & No & $-4.63 \mathrm{~cm} / \mathrm{s}$ & -2.52 \\
\hline 6 & $136.23 \mathrm{gmwol}$ & 0 & 0 & 47.12 & 2.72 & Low & 3.37 & $\begin{array}{l}0.00 \\
A^{2}\end{array}$ & Yo: & No & No & $-3.89 \mathrm{~cm} / \mathrm{s}$ & -3.50 \\
\hline 7 & $154.25 \mathrm{~g}$ mol & 1 & 1 & 48.90 & 2.51 & High & 260 & 20.23 & Yo: & No & No & $-4.93 \mathrm{cms}$ & -2.78 \\
\hline 8 & $134.22 \mathrm{gmol}$ & 0 & 0 & 4599 & 2.51 & Low & 3.50 & $0.00 \mathrm{~A}$ & Yo: & No & No & $-4.21 \mathrm{~cm} / \mathrm{s}$ & -3.63 \\
\hline 9 & $136.23 \mathrm{~g} \mathrm{~mol}$ & 0 & 0 & 45.22 & 2.63 & Low & 3.4 & $0.00 \mathrm{~A}$ & Yo: & No & No & $-3.95 \mathrm{~cm} / \mathrm{s}$ & -3.51 \\
\hline 10 & $250.36 \mathrm{gmol}$ & 4 & 0 & 80.47 & 3.22 & High & 3.35 & 4.76 & Yo: & No & No & $-5.52 \mathrm{~cm} / 5$ & -3.62 \\
\hline 11 & $266.25 \mathrm{gmol}$ & 6 & 3 & 6790 & 0.76 & High & 1.30 & 111.9 & No & No & No & $-6.23 \mathrm{~cm} / \mathrm{s}$ & -2.89 \\
\hline 12 & $154.25 \mathrm{gmol}$ & 1 & 1 & 48.50 & 2.46 & High & 246 & $\begin{array}{l}20.23 \\
A^{2}\end{array}$ & Yo: & No & No & $-5.47 \mathrm{~cm} / \mathrm{s}$ & -2.31 \\
\hline
\end{tabular}




\section{CONCLUSION}

Due to non-approved drugs at present, COVID-19 has emerged in the human population, in China, and is a potential threat to global health, worldwide. The present study focused on bioactive molecules from eucalyptus essential oil that may be used to inhibit the COVID-19 infection pathway. Jensenone and Cis-p-2-Menthen-1-ol exhibited highest affinity with Mpro protein. Therefore, we suggested that these molecules may represent potential treatment options and found in medicinal plants that may act as potential inhibitors of COVID19 Mpro. However, further studies should be conducted for the validation of these compounds using in vitro and in vivo models to pave a way for these compounds in drug discovery.

\section{Acknowledgment}

ADS want to thank the management for this support.

\section{References:}

[1] Goodger, J.Q.D., Senaratne, S.L., Nicolle, D., Woodrow, I.E. (2016): Correction: Foliar Essential Oil Glands of Eucalyptus Subgenus Eucalyptus (Myrtaceae) Are a Rich Source of Flavonoids and Related Non-Volatile Constituents. PLoS ONE 11 (5): e0155568. doi: 10.1371/journal.pone.0151432

[2] LiU, X., Wang, X-J. (2020). Potential inhibitors against 2019-nCoV coronavirus M protease from clinically 13 of 14 approved medicine. Journal of Genetics and Genomics 47 (2): 119-121. doi: 10.1016/j.jgg.2020.02.001

[3] LU, H. (2020): Drug treatment options for the 2019-new coronavirus (2019-nCoV). BioScience Trends 14 (1): 69-71. doi: 10.5582/bst.01020

[4] Rodríguez-Morales, P., Alfonso, J., MacGregor, K., Kanagarajah, S., Patel, D., SCHLAGENHAUF, P., (2020): Going global - Travel and the 2019 Novel Coronavirus. Travel Medicine and Infectious Disease 33: 101578. doi: 10.1016/j.tmaid.2020.101578

[5] Yang, L., Wen, K.S., Ruan, X., ZhaO, Y.X., Wei, F., Wang, Q. (2018). Response of plant secondary metabolites to environmental factors. Molecules 23 (4): 762. doi: $10.3390 /$ molecules 23040762

[6] Zakaryan, H., Arabyan, E., Oo, A., ZANDi, K. (2017): Flavonoids: promising natural compounds against viral infections. Archives of Virology 162 (9): 2539-2551. doi: 0.1007/s00705-017-3417-y

\section{Internet sources:}

http://lmmd.ecust.edu.cn/admetsar2/

https://mcule.com/apps/1-click-docking/

https://projects.biotec.tu-dresden.de/plip-web/plip/index

https://pubchem.ncbi.nlm.nih.gov/

http://sts.bioe.uic.edu/castp/index.html?2011

https://www.rcsb.org/ 
